\title{
Depression and Preference for Self-Focusing Stimuli After Success and Failure
}

\author{
Tom Pyszczynski \\ University of North Carolina at Chapel Hill
}

\author{
Jeff Greenberg \\ University of Arizona
}

\begin{abstract}
Depressed individuals, who tend to have large perceived-self/ideal-self discrepancies, have been shown to be particularly high in private self-consciousness. On the bases of this finding and of several converging theoretical perspectives, we hypothesized that depressives, unlike nondepressives, do not find self-focus more aversive after failure than after success, and thus either (a) show no differential preference for self-focusing stimuli after success versus after failure (weak hypothesis), or (b) prefer self-focusing stimuli after failure over self-focusing stimuli after success (strong hypothesis). Depressed and nondepressed college students succeeded or failed on a supposed test of verbal intelligence, and then worked on two sets of puzzles, one in the presence and one in the absence of a self-focusing stimulus (mirror). Whereas nondepressed subjects liked the mirror-associated puzzle more after success than after failure, depressed subjects did not; depressed subjects tended to like the mirrorassociated puzzle more after failure than after success. Nondepressed subjects also exhibited a self-serving pattern of attributions, viewing the test as less valid and luck as more responsible for their performance after failure than after success; depressed subjects showed no such differences. In consistency with their failure to use defensive strategies, depressed subjects showed a decrease in self-esteem after failure; nondepressed subjects showed no such change.
\end{abstract}

Although theoretical and empirical interest in the role of cognitive factors in depression has grown considerably in recent years, the role of focus of attention in maintaining and exacerbating depression has been largely ignored. This is unfortunate because, as Smith and Greenberg (1981) noted, a number of striking similarities exist between depressed individuals and individuals who are in a state of heightened private self-awareness. Specifically, both depressives and self-focused nondepressives show an increased self-evaluative tendency and lowered self-esteem (e.g., Beck, 1967; Duval \& Wicklund, 1972; Fenigstein, 1979; Ickes, Wicklund, \& Ferris, 1973; Laxer, 1964), intensified negative affect (e.g., Beck, 1967; Gibbons et al., 1985; Scheier \& Carver, 1977), an increased tendency to make internal attributions for negative outcomes, (e.g., Buss \& Scheier, 1976; Duval \& Wicklund, 1973; Kuiper, 1978; Rizley, 1978), particularly accurate

Requests for reprints should be sent to Tom Pyszczynski, Department of Psychology, Davie 013A, University of North Carolina at Chapel Hill, Chapel Hill, North Carolina 27514. self-reports (e.g., Alloy \& Abramson, 1979; Gibbons et al., 1985; Lewinsohn, Mischel, Chaplin, \& Barton, 1980; Nelson \& Craighead, 1977; Pryor, Gibbons, Wicklund, Fazio, \& Hood, 1977; Scheier, Buss, \& Buss, 1978), and an increased tendency to withdraw from tasks after an initial failure experience (e.g., Carver, Blaney, \& Scheier, 1979). Recently, a number of researchers, using a variety of indexes of both self-focus and depression, have shown the two variables to be positively correlated (Ingram \& Smith, 1984; Smith \& Greenberg, 1981; Smith, Ingram, \& Roth, in press): that is, that depressed individuals are especially prone to private self-awareness. These studies have consistently shown a correlation between depression and private but not public self-consciousness (cf. Fenigstein, Scheier, \& Buss, 1975). This research, along with the parallels noted earlier, suggests that self-focused attention may play a deleterious role in depression.

Given that self-awareness is considered to be a transitory state, it is therefore important to determine the precise conditions that encourage and discourage self-focus in depressed individuals. According to theories of self-awareness, a motivational mechanism 
regulates the self-focusing tendency. Thus selfawareness theorists propose that self-focused attention instigates an evaluative process by which one's standing on a given dimension is compared with whatever standard for that dimension is currently salient (Buss, 1980; Carver \& Scheier, 1981; Duval \& Wicklund, 1972; Wicklund, 1975). This comparison produces either positive or negative affect, depending on whether one exceeds or falls short of the salient standard. If one exceeds the standard, self-focus produces positive affect, and the individual seeks to maintain the self-focused state. The major theorists differ to some extent, however, with regard to responses to deficiencies. According to Duval and Wicklund (1972) and Wicklund (1975), if the discrepancy between self and standard is negative, self-focus produces negative affect, which then leads to avoidance of stimuli that bring on the self-focused state; if self-focus cannot be avoided, the individual then engages in attempts to reduce the discrepancy. Alternatively, Carver (1979) proposed that attempts at discrepancy reduction occur if the perceived probability of successful reduction is high, whereas avoidance is more likely if the perceived probability of successful reduction is low.

The results of a wide range of empirical investigations have supported the notion that self-focus instigates attempts at self-standard discrepancy reduction, especially when selffocus is unavoidable (see Carver \& Scheier, 1981, and Wicklund, 1975, for reviews). This research can be taken as indirect evidence that self-focus on negative discrepancies is aversive. In addition, researchers have supported this notion more directly by showing that individuals prefer self-focus after favorable outcomes to self-focus after unfavorable outcomes (Duval, Wicklund, \& Fine, reported in Duval \& Wicklund, 1972; Gibbons \& Wicklund, 1976; Greenberg \& Musham, 1981). Taken as a whole, these results suggest that self-focus is more aversive and thus more likely to be avoided when self-standard discrepancies are negative than when they are positive. Paradoxically, depressed individuals seem to be constantly oppressed by such perceived deficiencies in themselves, and yet they tend toward more rather than less self-focus than do nondepressed individuals (Ingram \& Smith,
1984; Smith \& Greenberg, 1981). This suggests quite simply that depressed individuals, unlike nondepressed individuals, do not avoid selffocus after negative events. Depressives may be relatively immune to the affect-inducing properties of self-focused attention. Thus their affective reactions to self-focus after negative outcomes may not differ from their affective reactions to self-focus after positive outcomes. We refer to this assertion as our weak hypothesis.

The possibility that depressives fail to find self-focus after negative outcomes aversive is consistent with a growing literature that demonstrates that depressives do not exhibit the defensive cognitions that nondepressed persons use in response to positive and negative outcomes. Specifically, it has been demonstrated that depressives do not exhibit the self-serving attributional bias that nondepressed individuals exhibit (e.g., Klein, Fencil-Morse, \& Seligman, 1976; Kuiper, 1978; Rizley, 1978; Seligman, Abramson, Semmel, \& von Baeyer, 1979); they do not exhibit the "illusion of control" over objectively uncontrollable events that nondepressed individuals exhibit (Alloy \& Abramson, 1979, 1982; Alloy, Abramson, \& Viscusi, 1981); they do not exhibit the exaggerated evaluations of their skills and competencies that nondepressed individuals exhibit (Lewinsohn et al., 1980); and they do not exhibit the ego-defensive bias in recall of positive and negative feedback that nondepressed individuals exhibit (Nelson \& Craighead, 1977). Taken as a whole, these findings are consistent with Freud's (1917/1957) and Bibring's (1953) observations that depression is often associated with a breakdown of normal defensive functions. To the extent that the aversion to selffocus after negative outcomes typically found in nondepressed individuals is part of a defensive mechanism that protects self-esteem, depressed individuals may fail to find such selffocus aversive because they have given up all concerns for and attempts at defending selfesteem.

One could also argue that rather than representing a passive relinquishing of self-esteem motives, the apparent lack of defensive distortions found in depressives may represent defensive strategies of a different type. A wide range of theoretical perspectives suggest that the self-derogating behavior frequently found 
in depressives may be a maladaptive attempt at coping with negative life events. For example, Rothbaum, Weisz, and Snyder (1982) proposed that individuals attempt to accomodate themselves to their environment (i.e., exert secondary control) when they believe they cannot alter their environment to suit their wishes (i.e., exert primary control). In other words, rather than actively attempting to exert control over environmental outcomes, such persons may attempt to control their affective responses to such events by adopting a passive, inner-directed orientation. Depressed individuals, who believe they cannot exert primary control, may thus attempt to achieve a secondary form of control, such as predictive control, by which they strive to predict outcomes before they occur; such an orientation may serve to guard against disappointment. Thus if such a person cannot produce desired outcomes, he or she can at least moderate extreme negative reactions by being aware of his or her inability to do so. By not avoiding selffocus after failure, depressives may keep their expectations low; thus failure may become more tolerable (cf. Pyszczynski, 1982).

Depressed individuals may also resort to interpretive control, an attempt to understand and find meaning in events. Thus after a negative outcome, such individuals may go to great lengths to explain why that outcome occurred. Indeed, Coyne, Metalsky, and Lavelle (1980) have found evidence that subjects made helpless in the lab "become preoccupied with explaining their inability" (p. 352). In a related vein, a number of theorists have suggested that depressed individuals have a great desire to maintain a negative self-image because it helps them maintain a stable identity, justify dependency on others, or make sense out of their bleak positions in the world (e.g., Adler, 1924; Becker, 1962, 1973; Gaylin, 1968). Freud, too, considered the self-derogating tendency to be an essential component of depression. He proposed that in depressed individuals, the superego heaps enormous amounts of criticism on the self (see Freud, 1917/1957, for his analysis of depression). Given Freud's conception that the superego serves to critically compare actual conduct with internalized standards, self-focus could be viewed as an instigation of superego functions.

Consideration of these theoretical perspec- tives on the function of self-derogating behavior suggests a stronger hypothesis concerning preference for self-focused attention in depressives. Depressed individuals may actually have a reversed preference, preferring self-focus after negative outcomes to self-focus after positive outcomes. Dwelling on the self-implications of negative outcomes but avoiding selffocus after positive outcomes may enable such individuals to maintain low expectations and a negative self-image; such cognitions provide ready explanations for failure and allow depressed individuals to avoid future disappointment and make minimal demands of themselves in the future.

Our study was designed to enable us to investigate these potential differences between depressed and nondepressed individuals in their preference for self-focus after success and failure. We hypothesized that in consistency with prior research, nondepressed individuals would prefer self-focusing stimuli after success to such stimuli after failure. We offered alternative hypotheses for the preferences of depressed individuals: The weak hypothesis was that depressed individuals would not differ in their preferences for self-focusing stimuli as a function of success and failure; the strong hypothesis was that depressed individuals would show a reversal of the pattern exhibited by nondepressed individuals, actually preferring self-focusing stimuli after failure to such stimuli after success. In other words, after success, nondepressives should like self-focus more than should depressives, whereas after failure, depressives should like self-focus more than should nondepressives.

To test these hypotheses, we used a modified version of Brockner and Walnau's (1981) procedure for measuring preference for self-focus. Depressed and nondepressed subjects worked on easily solvable or unsolvable anagrams (producing either success or failure) and were then given 3 min to work on each of two puzzles, one of which was worked on in the presence of a mirror. Subjects were then asked to indicate which of the two puzzles they preferred. We predicted an interaction whereby nondepressed subjects would prefer the mirrorassociated puzzle after success, but depressed subjects either would show no difference in preference for the puzzles (weak hypothesis) or would prefer the mirror-associated puzzle 
after failure (strong hypothesis). In addition, subjects' attributions for their anagram performance and other reactions to the test were assessed in an attempt to replicate earlier findings of a lack of other defensive maneuvers on the part of depressed subjects. Finally, to the extent that self-serving biases and aversion to self-focus after failure both function to protect self-esteem, and to the extent that depressed individuals do not use such strategies, one would expect depressed but not nondepressed subjects to show self-esteem deficits after failure. To test this hypothesis directly, we assessed self-esteem before and after test performance.

\section{Method}

\section{Subjects}

Subjects were selected on the basis of their scores on the Beck Depression Inventory (BDI; Beck, 1967), which was administered in several large lecture sections of an introductory psychology class. Individuals with BDI scores of 8 or less were classified as nondepressed, and individuals with BDI scores of 10 or above were classified as depressed. Mean BDI scores were 3.50 for subjects classified as nondepressed and 13.68 for subjects classified as depressed. From this initial pool, 36 female and 20 male students participated in the experiment within 2 weeks of the initial screenings.' Depressed and nondepressed subjects were randomly assigned to outcome conditions in a $2 \times 2$ (Nondepressed vs. Depressed $\times$ Success vs. Failure) factorial design. The experiment was conducted in individual sessions with each subject; the experimenter was blind to the subject's classification on the depression variable.

\section{Procedure}

On arriving for the experiment, subjects were seated and asked to read and sign an informed-consent form, in which we stated that the study was concerned with the verbal intellectual abilities of college students. They were then asked to fill out a questionnaire containing a 20 -item version of the Self-Valuation Triads test (SVT-pre; Gergen, 1962 , to be described in the dependent measure section), a relatively unobtrusive measure of self-esteem. They were then informed that the study was concerned with the verbal intellectual abilities of college students and that as part of the study, they would take the Thorndike Anagram Test and then later work on some sets of word puzzles.

The Thorndike Anagrams Test was described as "one of the best tests of verbal intelligence available." We manipulated performance outcome by giving half of the subjects a set of easily solvable four-letter anagrams and the other half a set of difficult and impossible five-letter anagrams. For the success subjects, 19 of the 20 anagrams were solvable, and we guaranteed a uniformly high level of performance by using a consistent pattern of letters for all 19 items. For the failure subjects, 14 of the 20 anagrams were unsolvable. On completion of the test, the experimenter scored the test and returned it to the subject, remarking in the success condition,
Hmm, it looks like you did very well. You got [x] correct. That's one of the highest scores I've seen. The average score is about $[x-5]$ correct.

In the failure condition the experimenter remarked,

$\mathrm{Hmm}$, it looks like you didn't do very well. You got $[\mathrm{x}]$ correct. I guess you're just not very good at this sort of thing. The average score is about $[x+5]$ correct.

The experimenter was blind to the outcome manipulation until she scored the tests.

At this point, the experimenter led the subject to a second room to work on the puzzles. A "Mirror Image Study" sign was attached to the door of the second room, and on entering, the experimenter remarked that because of a shortage of space, she had to share this room with another researcher. The room was $4 \times 3 \mathrm{~m}$ and contained two tables, on each of which was a puzzle set, at opposite ends of the room. One of the tables had a large $60 \times 50 \mathrm{~cm}$ mirror, directly facing the chair on which the subject would sit, and a sign, which read, "Please Do Not Move," taped above the mirror.

The experimenter then explained that the subject would work on each set of puzzles for $3 \mathrm{~min}$. The subject then was seated at the table without the mirror, read the instructions for the puzzle set, and worked on the puzzles for $3 \mathrm{~min}$. After this, the subject was asked to move to the table with the mirror, read the instructions for the second puzzle set, and work on the puzzles, again for $3 \mathrm{~min}$.

The puzzles were the adult games Perquackey (by Lakeside) and the Scrabble Sentence Cube Game (by Selchow \& Righter). Perquackey was referred to as the "word puzzle" and the Scrabble Sentence Cube Game was referred to as the "sentence puzzle." These puzzles were similar in that each required subjects to shake a set of dice and then form either words or sentences from their set. The puzzle associated with the mirror was counterbalanced such that for half of the subjects the word puzzle was placed in front of the mirror.

After completion of the second 3-min period, subjects were escorted back to the original room and asked to fill out a final questionnaire on which they indicated their ratings of liking for the puzzles, attributions for performance on the anagram test, another version of the SelfValuation Triads (the SVT-post measure; Gergen, 1962) and several other items concerning their reactions to the anagrams test. On completing this questionnaire, subjects were thoroughly debriefed and then dismissed.

\section{Dependent Measures}

The primary dependent measures were two items concerned with the subject's preference for self-focusing stimuli. The first, "Which of the two puzzles did you like the most?", was responded to on a 9-point scale on which 1 = sentence puzzles very much more, $5=$ both equal, and $9=$ word puzzles very much more. When we analyzed these data, the scales were reversed for subjects for whom the

\footnotetext{
'Preliminary analyses on the main dependent measures revealed no main effects or interactions involving sex of subject. Thus this variable was not included in the analyses reported in this article.
} 
sentence puzzles were associated with the mirror so that a high score always reflected preference for the mirrorassociated puzzles. Subjects were also asked the open-ended question "If you had to choose between one puzzle or the other to work on for an additional ten minutes, which would you choose?" so as to get a direct measure of their choice between the two puzzles. Subjects also indicated how pleased they were with their performance on the anagram test, rated the validity of the test and their level of verbal intellectual ability, and attributed their performance to ability and luck, by responding on 9-point scales ( 1 = low, 9 = high).

We measured self-esteem before subjects took the anagram test and after they worked on the puzzles with 20 item versions of the Self-Valuation Triads (Gergen, 1962; Jones, Rhodewalt, Berglas, \& Skelton, 1981). Each of the 20 triads consists of one positive self-descriptive statement (e.g., "appears self-assured"), one negative statement (e.g., "bothered by unpleasant events"), and one neutral statement (e.g., "prefers football over baseball"). Subjects were to divide a total of 10 points among each of the three statements on the basis of the extent to which each statement was, in relation to the other statements in the triad, descriptive of themselves; more points were assigned to those items within a triad that were relatively more selfdescriptive. Alternative versions of the triads were used as pre- and postmeasures of self-esteem. We computed selfesteem scores by subtracting the total points assigned to the 20 negative items from the total points assigned to the 20 positive items within each version of the scale.

\section{Results}

\section{Manipulation Checks}

Success subjects clearly solved more anagrams than did failure subjects $(M s=18.75$ and 4.57 , respectively). There was no overlap in the two distributions, and performance did not vary as a function of depression. Success subjects also reported that they were more pleased with their performance on the test than were failure subjects, as evidenced by a main effect of outcome, $F(1,52)=144.54, p<.0001$ ( $M \mathrm{~s}=7.75$ and 2.57 , respectively). Thus the outcome manipulation was clearly successful. Although a main effect of depression was also obtained on the latter measure, $F(1,52)=$ $5.01, p<.03$, the interaction did not approach significance $(F<1.0)$. Depressed subjects indicated that they were less pleased with their performance than were nondepressed subjects, regardless of whether they succeeded or failed ( $M \mathrm{~s}=4.68$ and 5.64, respectively). This finding supports the validity of our depression categorization in that it is consistent with clinical observations that depressives find little pleasure in success and great displeasure with failure (e.g., Beck, 1967). Another finding that was
Table 1

Mean Ratings of Liking for the Self-Focusing Puzzle and Proportion of Subjects Choosing the Self-Focusing Puzzle as a Function of Depression and Performance Outcome

Performance outcome

\begin{tabular}{lcc}
\multicolumn{1}{c}{ Measure } & Success & Failure \\
\cline { 2 - 3 } $\begin{array}{l}\text { Liking for self-focusing } \\
\text { puzzles }\end{array}$ & & \\
$\begin{array}{l}\text { Nondepressed } \\
\text { Depressed }\end{array}$ & 6.07 & 4.14 \\
$n$ per cell & 4.79 & 6.43 \\
Proportion of subjects & 14 & 14 \\
$\quad$ choosing self- & & \\
$\quad$ focusing puzzle & .71 & .50 \\
Nondepressed & .29 & .57 \\
Depressed & 14 & 14 \\
$n$ per cell & & \\
\hline
\end{tabular}

Higher scores indicate greater liking.

also consistent with this categorization was that depressed subjects exhibited lower self-esteem than did nondepressed subjects $(M s=30.73$ and 67.68, respectively), $F(1,52)=11.89$, $p<.001$.

\section{Preference for Self-Focusing Stimuli}

Mean ratings of liking for the self-focusing puzzle and proportions of subjects choosing the self-focusing puzzle for later work are presented in Table 1. An analysis of variance (ANOVA) performed on the liking item revealed only the predicted Depression $\times$ Outcome interaction, $F(1,52)=5.77, p=.02$. Inspection of Table 1 suggests that the pattern of liking for the mirror-associated puzzle as a function of outcome was reversed for depressed and nondepressed subjects. Planned pairwise comparisons ${ }^{2}$ in which we used an error term that was based on the mean square withinsubjects factor from the ANOVA revealed that in consistency with prior findings, nondepressives liked the self-focusing puzzle after success more than they did after failure, $t(26)=1.85$, $p<.05$. Also in consistency with predictions, depressed subjects tended to like the self-focusing puzzle after failure more than they did

\footnotetext{
${ }^{2}$ Planned pairwise comparisons based on theoretically derived predictions were assessed with one-tailed $t$ tests if differences were in the predicted direction and significant overall ANOVA effects were obtained (Winer, 1971).
} 
Attributions and Reactions to the Test as a Function of Depression and Performance Outcome

\begin{tabular}{cccccc}
\hline & \multicolumn{2}{c}{ Nondepressed } & & \multicolumn{2}{c}{ Depressed } \\
\cline { 2 - 3 } \cline { 5 - 6 } Item & Success & Failure & & Success & Failure \\
\hline Validity of test $^{\mathrm{s}}$ & 6.00 & 4.29 & & 4.86 & 5.36 \\
Verbal intelligence $^{\mathrm{b}, c}$ & 7.14 & 6.00 & & 6.36 & 4.93 \\
Ability attribution $^{\mathrm{b}, \mathrm{c}}$ & 6.64 & 4.07 & & 5.07 & 3.64 \\
Luck attribution $^{\mathbf{a}}$ & 1.79 & 3.79 & & 2.93 & 2.79 \\
\hline
\end{tabular}

Note. Higher scores reflect higher ratings on the dimension in question.

a Statistically significant interaction. ${ }^{b}$ Statistically significant main effect of depression. ${ }^{\mathrm{c}}$ Statistically significant main effect of outcome.

after success, $t(26)=1.54, p<.10$. In the failure condition depressed subjects clearly liked the self-focusing puzzle more than did nondepressed subjects, $t(26)=2.20, p<.025$. Although the means were in the appropriate direction, the difference between depressed and nondepressed subjects in the success condition did not approach significance, $t(26)=1.24$, $p>.10$.

Dichotomous choice responses were subjected to a weighted least squares analysis (Grizzle, Starmer, \& Koch, 1969), and, again, we found only the predicted Depression $X$ Outcome interaction, $\chi^{2}(1, N=56)=3.88$, $p<.05$. Although the pattern of proportions suggests a reversal in the preferences exhibited by the depressed and nondepressed subjects, pairwise contingency chi-square tests showed that the only significant simple effect was that depressed subjects were less likely to choose the self-focusing puzzle after success than were nondepressed subjects, $\chi^{2}(1, N=28)=5.14$, $p<.05$; no depression-related differences were found in choice of puzzles in the failure condition. Taken together, the two measures of preference for self-focusing stimuli provide substantial support for the weak hypothesis that whereas nondepressed individuals tend to show greater preference for self-focusing stimuli after success than after failure, depressed individuals do not show this preference; although clear support for the strong hypothesis was not obtained, the data suggest that there may be a tendency for depressives to actually like self-focus after failure better than self-focus after success. ${ }^{3}$ Looked at differently, the results suggest that after failure, depressives like selffocus more than do nondepressives, and after success they are less likely to choose self-focus than are nondepressives.

\section{Attributions and Reactions to the Anagram Test}

In consistency with prior research, we hypothesized that whereas nondepressives would show a pattern of self-serving attributions and reactions to the test, depressives would not show such a pattern. As predicted, Depression $\times$ Outcome interactions were found on attributions to luck, $F(1,52)=4.75, p<.04$, and ratings of the validity of the test, $F(1,52)=$ $3.85, p=.055$. Mean responses to the attribution and reaction items may be found in Table 2. Planned pairwise comparisons revealed that nondepressed subjects viewed luck as more responsible for failure than for success, $t(26)=2.89, p<.005$, and viewed the test as more valid after success than after failure, $t(26)=2.15, p<.025$; depressed subjects failed to show differences on these items as a function of outcome (both $t \mathrm{~s}<1$ ). Main effects of both depression and outcome were found on subjects' ratings of their verbal intellectual ability, $F(1,52)=6.69, p<.02$, and $F(1,52)=12.82$, $p<.001$, respectively, and on their attributions for their performance on the test to their level of ability, $F(1,52)=4.13, p<.05$, and $F(1$, $52)=16.52, p<.001$, respectively. Subjects rated their verbal intelligence as lower and as

\footnotetext{
${ }^{3}$ This should not be taken to imply that depressives necessarily enjoy self-focus after failure. Rather, the obtained difference may reflect less aversion to self-focus after failure than after success. This issue is taken up in the discussion.
} 
less responsible for their performance after failure than they did after success. In addition, depressed subjects rated their verbal intelligence as lower and themselves as less responsible for their performance than did nondepressed subjects. These findings provide additional support for the effectiveness of the outcome manipulation.

\section{Self-Esteem}

Pre- and post-self-esteem scores were subjected to a $2 \times 2 \times 2$ ANOVA, in which depression and outcome were treated as betweensubjects factors and pre-post-self-esteem scores were treated as a within-subjects factor. Mean self-esteem scores may be found in Table 3. As reported earlier, a main effect of depression was found: Depressed subjects exhibited lower self-esteem than did nondepressed subjects. Although the three-way interaction did not attain statistical significance, $F(1,52)=2.27, p=.138$, planned pairwise comparisons in which we used individual error terms (Winer, 1971) revealed a significant change in self-esteem only in the depressedfailure condition, $t(13)=2.84, p<.01$ (all other $t s<1$ ). This finding is consistent with the overall tendency of depressed subjects to fail to exhibit the defensive reactions used by their nondepressed counterparts. To the extent that defensive maneuvers are not used, subjects would be expected to show a loss of self-esteem after failure.

\section{Discussion}

Our findings support the hypothesis that depressives, unlike nondepressives, do not prefer self-focus after success to self-focus after failure. Thus it is clear that depressed and nondepressed individuals differ in their reactions to self-focusing stimuli after success and failure. Depressed subjects liked the mirrorassociated puzzle after failure more than did nondepressed subjects and were less likely than nondepressed subjects to choose the mirrorassociated puzzle after success. In addition, whereas nondepressed subjects showed the typical pattern of liking the mirror-associated puzzle more after success than after failure (cf. Duval, Wicklund, \& Fine, reported in Duval \& Wicklund, 1972; Gibbons \& Wicklund,
Table 3

Pre- and Postmeasures of Self-Esteem as a Function of Depression and Performance Outcome

\begin{tabular}{cccccc}
\hline & \multicolumn{2}{c}{ Nondepressed } & & \multicolumn{2}{c}{ Depressed } \\
\cline { 2 - 3 } \cline { 5 - 5 } $\begin{array}{c}\text { Self-esteem } \\
\text { measure }\end{array}$ & Success & Failure & Success & Failure \\
\hline Pre & 66.64 & 70.64 & 47.21 & 39.86 \\
Post & 64.14 & 69.29 & 48.00 & 27.86 \\
\hline
\end{tabular}

Note. Higher scores reflect greater self-esteem.

1976; Greenberg \& Musham, 1981), depressed subjects clearly did not. To some extent, the data suggest a possible reversal of the typical pattern on the part of depressives, in that they tended to like self-focus after failure better than self-focus after success; this latter effect must be viewed as merely suggestive, however, because the pairwise comparison was of only marginal statistical significance $(p<.10)$.

These differences in preferences for the puzzles were presumably mediated by the affect generated by self-focused attention after success or failure on the anagram test. The self-focused attention brought on by the subject's confrontation with his or her mirror image while working on one of the puzzles presumably increased the salience of the comparison of his or her performance on the anagram test with whatever standard he or she held regarding such performance. Depending on the subject's performance on the test, mirror presence thus produced enhanced positive or enhanced negative affect, which then led to increased or decreased liking for the puzzle that the subject was working on at the time.

The intriguing aspect of our findings is that whereas nondepressed subjects' behavior generally followed the predictions of self-awareness theorists (Carver, 1979; Duval \& Wicklund, 1972 ) in that they liked the mirror-associated puzzle more after success than after failure, depressed subjects' behavior did not. Given that depressed subjects in our study were shown to have lower self-esteem than nondepressed subjects had, and that depression is generally associated with feelings of failure, helplessness, and worthlessness, self-awareness theorists would predict even greater aversion to self-focusing stimuli after failure in depressives than in nondepressives. Contrary to this 
reasoning, the pattern of results suggests the possibility of a counterdefensive preference in the depressed, at least hinting at Freud's (1917) 1957) paradoxical assertion that "The self-tormenting in melancholia . . . is without doubt enjoyable" (p. 60). Thus one might suggest that for depressed subjects in our study, self-focus after success produced feelings of anxiety, uncertainty, and apprehension regarding incorporation of the outcome into their relatively safe, unassailable negative self-images. This reasoning is supported by the fact that after success, depressives were less likely to choose the mirror-associated puzzle than were nondepressives. By contrast, self-focus after failure may have been less threatening and even comforting because it did not call for revision of their negative self-evaluations. As we noted in the introduction, a wide range of theoretical perspectives converge on the notion that the self-derogating tendencies of depressives may serve the function of maintaining a safe, stable level of self-evaluation, free from the affective extremes that might result from attempts at maintaining a more positive self-image (Adler, 1924; Becker, 1962, 1973; Gaylin, 1968; Rothbaum et al., 1982). The finding that after failure depressives liked the mirror-associated puzzle more than did nondepressives is consistent with this possibility.

We are not suggesting that depressives experience obvious signs of pleasure with failure or that, given a choice, they would choose failure over success. Such a claim would clearly run counter to the sadness and negative affect that are the defining features of depression. Rather, we suggest that there are costs associated with success and benefits associated with failure that may lead depressives to avoid selffocus after success and to like self-focus after failure. As a consequence of this depressive self-focusing style, depressives may derive less pleasure from success and more displeasure from failure than nondepressed individuals might. Our finding that depressed subjects were less pleased with their performance on the test than were nondepressed subjects, regardless of outcome, is consistent with this possibility. Thus these self-focusing tendencies may play a substantial role in exacerbating the downward spiral of depression that has been noted by clinical psychologists (e.g., Beck, 1967).
In addition to suggesting a unique depressive style of self-focusing, our findings also replicated the frequently reported lack of defensive distortions in performance-relevant cognitions among depressives (e.g., Alloy \& Abramson, 1979, 1982; Klein et al., 1976; Kuiper, 1978; Rizley, 1978). Whereas nondepressed subjects viewed the test as less valid and luck as more responsible for their performance after failure than after success, depressed subjects showed no such differences. Taken as a whole, our findings strongly suggest a failure to defend self-esteem on the part of depressives. Another finding that was consistent with this notion was that depressed but not nondepressed subjects showed a loss of self-esteem after failure. Because self-esteem was not protected by depressed subjects, a loss of self-esteem would logically follow from failure. Although previous researchers have assumed such a consequent effect of failure and a lack of defensiveness on self-esteem, this is the first study to demonstrate both an absence of defensive strategies and the deleterious effect on self-esteem in the same context.

In summary, our findings, along with those of Smith and Greenberg (1981) and Ingram and Smith (1984), clearly suggest differences between the self-focusing tendencies of depressed and nondepressed individuals. In addition, accumulating evidence suggests that excessive self-preoccupation may mediate the performance deficits found in many laboratory experiments after experiences with failure, uncontrollable outcomes, or other stressors (e.g., Brockner \& Hulton, 1978; Coyne et al., 1980; Jacobson \& Anderson, 1982; Kuhl, 1981; Smith, Ingram, \& Brehm, 1983). It seems reasonable to suggest that the self-focusing tendencies found in depressives are likely to encourage negative affect, unfavorable self-attributions, negative expectations, and low self-esteem. Thus the depressive self-focusing style may play a major role in the development, maintenance, and exacerbation of the cognitive, emotional, and performance deficits commonly associated with depression. Additional investigations into the conditions under which depressed individuals seek and avoid self-focused attention, along with studies of the consequences of these self-focusing tendencies, may reveal important clues as to the cognitive functioning of depressives and the 
instrumental functions of their cognitions and behaviors.

\section{References}

Adler, A. (1924). The practice and theory of individual psy. chology. London: Kegan Paul.

Alloy, L., \& Abramson, L. (1979). Judgment of contingency in depressed students: Sadder but wiser? Journal of Experimental Psychology: General, 108, 441-485.

Alloy, L., \& Abramson, L. (1982). Induced mood and the illusion of control. Journal of Personality and Social Behavior, 41, 1129-1140.

Alloy, L., Abramson, L., \& Viscusi, D. (1981). Learned helplessness, depression, and the illusion of control. Journal of Personality and Social Psychology, 42, 11141126.

Beck, A. T. (1967). Depression: Clinical, experimental, and theoretical aspects. New York: Hoeber.

Becker, E. (1962). The birth and death of meaning. New York: Free Press of Glencoe.

Becker, E. (1973). The denial of death. New York: Free Press.

Bibring, E. (1953). The mechanism of depression. In P. Greenacre (Ed.), Affective disorders (pp. 13-14). New York: International Universities Press.

Brockner, J., \& Hulton, A. J. B. (1978). How to reverse the vicious cycle of low self-esteem: The importance of attentional focus. Journal of Personality and Social Psychology, 14, 564-578.

Brockner, J., \& Walnau, L. B. (1981). Self-esteem, anxiety, and the avoidance of self-focused attention. Journal of Research in Personality, 15, 227-291.

Buss, A. (1980). Self-consciousness and social anxiety. San Francisco: W. H. Freeman.

Buss, A., \& Scheier, M. (1976). Self-consciousness, selfawareness, and self-attribution. Journal of Research in Personality, 10, 463-468.

Carver, C. (1979). A cybernetic model of self-attention processes. Journal of Personality and Social Psychology, 37. 1251-1281.

Carver, C. S., Blaney, P. H., \& Scheier, M. F. (1979). Reassertion and giving up: The interactive role of self-directed attention and outcome expectancy. Journal of Personality and Social Psychology, 37, 1859-1870.

Carver, C., \& Scheier, M. (1981). Attention and self-regulation. New York: Springer-Verlag.

Coyne, J. C., Metalsky, G. I., \& Lavelle, T. L. (1980). Learned helplessness as experimenter-induced failure and its alleviation with attentional redeployment. Journal of Abnormal Psychology, 89, 350-357.

Duval, S., \& Wicklund, R. (1972). A theory of objective self-awareness. New York: Academic Press.

Duval, S., \& Wicklund, R. (1973). Effects of objective selfawareness on attributions of causality. Journal of Experimental Social Psychology, 9. 17-31.

Fenigstein, A. (1979). Self-control, self-attention, and social interaction. Journal of Personality and Social Psychology, $37,75-86$.

Fenigstein, A., Scheier, M., \& Buss, A. (1975). Public and private self-consciousness: Assessment and theory. Journal of Consulting and Clinical Psychology, 43, 522527.

Freud, S. (1957). Mourning and melancholia. In J. Stracbey
(Ed. \& Trans.), The complete psychological works of Sigmund Freud (Vol. 14, pp. 239-258). London: Hogarth Press. (Original work published in 1917)

Gaylin, W. (1968). The meaning of despair: Psychoanalytic contributions to the understanding of depression. New York: Science House.

Gergen, K. J. (1962). Interaction goals and personalistic feedback as factors affecting the presentation of self. Unpublished doctoral dissertation, Duke University.

Gibbons, F. X., Smith, T. W., Ingram, R. E., Pearce, K., Brehm, S. S., \& Schroeder, D. J. (1985). Self-awareness and self-confrontation: Effects of self-focused attention on members of a clinical population. Journal of Personality and Social Psychology, 48, 662-675.

Gibbons, F. X., \& Wicklund, R. (1976). Selective exposure to self. Journal of Research in Personality, 10, 98-106.

Greenberg, J., \& Musham, C. (1981). Avoiding and seeking self-focused attention. Journal of Research in Personality, $15,191-200$.

Grizzle, J. E., Starmer, C. F., \& Koch, G. G. (1969). Analysis of categorical data by linear models. Biometrics, 25 . 489-504.

Ickes, J., Wicklund, R., \& Ferris, C. (1973). Objective selfawareness and self-esteem. Journal of Experimental Social Psychology, 9, 202-219.

Ingram, R. E., \& Smith, T. W. (1984). Depression and internal versus external focus of attention. Cognitive Therapy and Research, 8, 139-151.

Jacobson, N. S., \& Anderson, E. A. (1982). Interpersonal skill and depression in college students: An analysis of the timing of self-disclosures. Behavior Therapy, 13, 271282.

Jones, E. E., Rhodewalt, F., Berglas, S., \& Skelton, J. A. (1981). Effects of strategic self-presentation in subsequent self-esteem. Journal of Personality and Social Psychology, $41,407-421$.

Klein, D. C., Fencil-Morse, E., \& Seligman, M. E. P. (1976). Depression, learned helplessness, and attribution of failure. Journal of Personality and Social Psychology, $33,508-516$.

Kuhl, J. (1981). Motivational and functional helplessness: The moderating effect of state versus action orientation. Journal of Personality and Social Psychology, 40, 155170.

Kuiper, N. (1978). Depression and causal attributions for success and failure. Journal of Personality and Social Psychology, 36, 236-246.

Laxer, R. (1964). Self-concept changes of depressed patients in general hospital treatment. Journal of Consulting Psychology, 28, 214-219.

Lewinsohn, P., Mischel, W., Chaplin, W., \& Barton, R. (1980). Social competence and depression: The role of illusory self-perceptions. Journal of Abnormal Psychology, 89, 203-212.

Nelson, R. E., \& Craighead, W. E. (1977). Selective recall of positive and negative feedback, self-control behaviors, and depression. Journal of Abnormal Psychology, 86, 379-388.

Pryor, J., Gibbons, F., Wicklund, R., Fazio, R., \& Hood, R. (1977). Self-focused attention and self-report validity. Journal of Personality, 45, 513-527.

Pyszczynski, T. (1982). Cognitive strategies for coping with uncertain outcomes. Journal of Research in Personality. $16,386-399$. 
Rizley, R. (1978). Depression and distortion in the attribution of causality. Journal of Abnormal Psychology, 87 , 32-48.

Rothbaum, F., Weisz, J. R., \& Snyder, S. S. (1982). Changing the world and changing the self: A two-process model of perceived control. Journal of Personality and Social Psychology, 42, 5-37.

Scheier, M., Buss, A., \& Buss, D. (1978). Self-consciousness, self-report of aggressiveness, and aggression. Journal of Research in Personality, 12, 133-140.

Scheier, M., \& Carver, C. (1977). Self-focused attention and the experience of emotion: Attraction, repulsion, elation, and depression. Journal of Personality and Social Psychology, 35, 625-636.

Seligman, M. E. P., Abramson, L., Semmel, A., \& von Baeyer, C. (1979). Depressive attribution style. Journal of Abnormal Psychology, 88, 242-248.
Smith, T. W., \& Greenberg, J. (1981). Depression and selffocused attention. Motivation and Emotion, 5, 323-331. Smith, T. W., Ingram, R. E., \& Brehm, S. S. (1983). Social anxiety, anxious preoccupation, and recall of self-relevant information. Journal of Personality and Social Psychology, 44, 1276-1283.

Smith, T. W., Ingram, R. E., \& Roth, D. L. (in press). Selffocused attention and depression: Self-evaluation, affect, and life-stress. Motivation and Emotion.

Wicklund, R. (1975). Objective self-awareness. In L. Berkowitz (Ed.), Advances in experimental social psychology (Vol. 8, pp. 233-275). New York: Academic Press.

Winer, B. J. (1971). Statistical principles in experimental design (2nd ed.). New York: McGraw-Hill.

Received June 21, 1983 Revision received June 11, 1984 